\title{
Pasture Problems
}

$\mathrm{T}$

HE many problems connected with cultivated grassland have recently received considerable emphasis. The International Grassland Congress, meeting at Aberystwyth in July, brought together some four hundred delegates, and further discussion of the subject took place during the Nottingham meeting of the British Association at a joint symposium of Sections $K$ (Botany) and $\mathbf{M}$ (Agriculture). An outline of the range of problems there discussed may prove of some general interest.

Grassland problems are largely determined by the perennial nature of the crop, which is a mixture of several species that are in constant competition with one another. These species settle down to a certain equilibrium among themselves, but this is easily upset by changes in the environmental conditions. Rainfall, temperature, sunshine and drought all play their part in encouraging some species at the expense of others, so causing either temporary or permanent changes in the balance of composition of the herbage. The quality and type of herbage are also very dependent upon the general management of manuring and grazing. Uncultivated grassland tends to become very rough and often develops a layer of peat on the surface, but with correct grazing a more even sward is obtained and the more valuable species are encouraged. Land that is always cut for hay bears a different flora from that which is grazed, owing to the variation in the response of species and the two methods of treatment. The time of seeding is also an important factor, and helps to determine the question of survival under cultivation. Wild white clover is a most valuable feeding plant, and is encouraged where land is properly grazed so that competition for light and air is reduced to a minimum.

Of recent years, the work of the Welsh Plant Breeding Station at Aberystwyth has shown the importance of selecting the varieties and strains of grasses that are appropriate for the particular purpose for which they are required. Pasture types and hay types of the same species are radically different in their habits, and success or failure in establishing new areas of grassland largely depends upon the selection of the seeds sown.

In sowing down new pastures, the type of mixture to be used presents its own problems. Complex mixtures of many species and simple mixtures of few species each have their advocates, and no definite ruling can be made as to which is prefer- able. Much depends upon environment and upon the object that it is desired to attain. Experiments and analyses carried on at Rothamsted for ten years, on land sown with a variety of seeds mixtures, have shown that the ultimate composition of the sward is very similar, regardless of the simplicity or complexity of the mixture initially sown. Some species are short lived, and though they may prove useful in providing grazing for the first year or two, they soon disappear, and their place is taken either by some other constituent of the original seeds mixture or by interloping species which establish themselves naturally. The balance existing between the groups consisting of grasses, leguminous and miscellaneous species may be entirely upset by prolonged drought, which in some cases may kill out the wild white clover, leaving bare spaces which are often invaded later by grass.

In addition to climatic variations, the grazing animal plays a most important part in the development of a sward. The various types of plants in a pasture are all in keen competition, and any factor which weakens one species gives the others a better chance. The grazing animal naturally eats down the most palatable species first, leaving the inferior plants alone except in times of scarcity. The lack of palatability of the latter plants thus affords them protection from grazing and so enables them to increase unduly. Very careful manipulation of the grazing is necessary to prevent this undesirable change in the balance of the species, and controlled grazing periods, together with artificial feeding of the animals at certain critical periods of the year, are necessary to keep the herbage at its best.

During the discussion at Nottingham, special emphasis was laid on the interdependence of the various principles of grassland management. Improvement may be considered from the point of view of the botanical composition of the herbage, pasture and stock management and soil fertility, but whatever is done in one direction is reflected in the reaction of the grassland as a whole. Methods of improvement and management vary in temporary and permanent pastures, and the botanical composition and the yield respond to the contrasting systems of management.

An outstanding problem is the difficulty of getting an accurate measurement of the value of grassland from the point of view of its productivity and feeding capacity. Empirical observations of 
the herbage and the stock afford a useful guide to the skilled farmer, but more accurate and quantitative information is necessary for the true comparison of different systems of management. The accurate assessment of yield presents many difficulties, as estimates obtained by continuous cutting to simulate grazing are misleading, since the period and intensity of actual grazing have very far-reaching effects on the sward. In order, therefore, to simulate grazing conditions as closely as possible, experiments of somewhat complex design are necessary, in which there is sufficient replication to permit grazing over the greater part of the experimental period, with infrequent cuts for the actual determination of yield. The type of stock used and variation in seasonal conditions also play their part in complicating the problem.

In the open discussion at the end of the symposium, the question was raised as to the possibility of laying down some clear directions for the practical man in the management of his sward. From the nature of the case, however, this is an impossibility, as the problems are so complex and the correct methods of management are so diverse. Treatments that are effective in one place, on one type of soil or under certain climatic conditions may be quite unsuccessful elsewhere or in other seasons. Careful observation of the effect of grazing on the sward, together with intelligent use of the results of such observation, are essential for the successful production of first-class pastures providing feed of high nutritive value. Furthermore, recent developments in the improvement of wild hill pastures along economic lines have opened up great possibilities for extended and profitable grazing, provided the active co-operation of the interested farming community is forthcoming.

WinifRed E. Brenchley.

\section{Zoological Expedition to the Oasis of Siwa, Egyptian Libya}

\section{By Joseph Omer-Cooper, Rhodes University College, Grahamstown, South Africa}

$\mathrm{T}$ HE Armstrong College Expedition to Siwa, consisting of Dr. Malcolm Cameron, Mr. C. L. Smith and myself was financed by the Royal Society, the Godman Exploration Fund, the Percy Sladen Trust, the British Museum (Natural History) and the Armstrong College Research Fund. Its object was the study of a typical Libyan oasis. We left England in March and returned in October 1935, after spending six months in the Libyan Desert and achieving all our objectives. Transfer from the staff of the Department of Zoology, Armstrong College, Newcastle-on-Tyne, to Grahamstown, South Africa, has been the principal cause of delay in presenting a preliminary report of the Expedition's results.

Siwa is watered by more than two hundred wells and springs. These in many cases flow into storage reservoirs from which the gardens are irrigated. The irrigation waters ultimately flow into pools or lakes from which there is no outlet. These are saline, and if large are known as 'birkets'. The water of the springs is thermal, the bottom water varying from $25^{\circ}$ to $29^{\circ} \mathrm{C}$. The salinity, which is slightly more variable, appears to be affected by the proximity of the birkets. In Siwa the larger springs, in which concentration by evaporation was negligible, had a chlorine content of 0.685-1.475 gm. chlorine per litre. The water contains little oxygen. Smith examined water from pipe wells, so obtaining pure samples of the subterranean water, and found only 0.105 c.cm. oxygen per litre. The water is supersaturated with gas which is more than 97 per cent nitrogen ; the residue being oxygen, carbon dioxide and inert gases. As the springs in several other Egyptian oases have the same peculiarities, it is probable that the water is derived from one great subterranean source.

The North African subterranean waters contain a considerable fauna, but no subterranean forms have been recorded from Egypt. This curious fact is adequately explained by the small oxygen content. This also explains the absence of the indigenous Siwan Cyprinodont fish from the larger springs, and the failure of Dr. H. Faouzi to introduce Tilapia into these springs, which appear excellently suited to them.

In certain springs the Cyprinodonts have the swim bladder much swollen and are unable to submerge. Some fish are almost globular. This is no doubt due to the water being supersaturated with nitrogen. 